\title{
BMJ Global Health Population health, economics and ethics in the age of COVID-19
}

\author{
Sanjay G Reddy
}

To cite: Reddy SG.

Population health, economics and ethics in the age of COVID-19. BMJ Global Health 2020;5:e003259. doi:10.1136/ bmjgh-2020-003259

Received 26 June 2020 Accepted 28 June 2020

\section{Check for updates}

(C) Author(s) (or their employer(s)) 2020. Re-use permitted under CC BY-NC. No commercial re-use. See rights and permissions. Published by BMJ.

Economics, The New School for Social Research, New York, New York, USA

Correspondence to Professor Sanjay G Reddy; reddysanjayg@gmail.com

\section{ABSTRACT}

Are the steps that have been taken to arrest the spread of COVID-19 justifiable? Specifically, are they likely to have improved public health understood according to widely used aggregate population health measures, such as Quality Adjusted Life Years (QALYs) and Disability Adjusted Life Years (DALYs) as much or more than alternatives? This is a reasonable question, since such measures have been promoted extensively in global and national health policy by influential actors, and they have become almost synonymous with quantification of public health. If the steps taken against COVID-19 did not meet this test, then either the measures or the policies must be re-evaluated. There are indications that policies against COVID-19 may have been unbalanced and therefore not optimal. A balanced approach to protecting population health should be proportionate in its effects across distinct health concerns at a moment, across populations over time and across populations over space. These criteria provide a guide to designing and implementing policies that diminish harm from COVID-19 while also providing due attention to other threats to aggregate population health. They should shape future policies in response to this pandemic and others.

Were the dramatic steps taken around the world to address the risks posed by COVID-19 justified? There has been a widespread presumption that they were, but can this be sustained after considered evaluation? Specifically, have they enhanced the 'public health', and if so, have they done so more than alternative approaches could have done? How should the answers to these questions influence what we do prospectively?

Global health policy has long focused on describing how the ill health of populations can be attributed to different sources of death and disease. A prime motivation has been to understand what interventions would provide the greatest benefit to population health. ${ }^{1-5} \mathrm{An}$ army has calculated such measures as QALYs and DALYs. Although measures of this kind have been employed in health policy in the developed world, they have likely been most consequential in poorer countries, where they have been pervasively promoted as a guide to priorities by health policy specialists,

\section{Summary box}

Measures that seek to describe the overall health of a population, taking note of all of the different risks of death and sickness that are present, have been used extensively in recent years to evaluate global and national health policies.

- We ask whether the steps taken to address the COVID-19 emergency have, according to such measures, promoted national and global public health, as compared with alternative policies.

- It is too early to answer this question with full assurance but there are indications that the sweeping steps that have been taken may not meet this test.

- An approach that furthers aggregate population health to the greatest extent must be proportionate in its treatment of different threats to health, different populations and different points in time and space. Such proportionality is demanded by most reasonable ethical frameworks.

- Proportionality should be a focus of attention when adjusting the response to the current pandemic and when formulating responses to future pandemics. Decision-makers can anticipate scenarios and adopt flexible policies even in the face of inadequate information and models.

international organisations and foundations. It may not be an exaggeration to say that, despite controversies, ${ }^{6}{ }^{7}$ such measures have become the currency of global health policy $^{89}$ and the dominant way of quantifying what the public health is, everywhere. It does not therefore require any agreement with the philosophy underlying such measures to find it useful to ask, 'What would applying them tell us about the current strategy of dealing with COVID-19?' We focus here on the efforts taken after complete suppression of the disease worldwide appeared no longer readily possible.

\section{THE AGGREGATE POPULATION HEALTH PERSPECTIVE}

Does the aggregate population health perspective (APHP) referred to above, that has been so widely applied to other health 
conditions and priorities, especially where 'distant others' ${ }^{10}$ are concerned, provide justification for the steps in response to COVID-19 which have been taken in individual countries or globally? If not, this implies that either the strategies adopted should be revised to reflect the APHP, or this perspective does not provide a suitable guide to action in response to the disease. The question therefore draws attention to whether the framework that has been most influentially applied ${ }^{11}$ to shape health policy for 'them', without exceptions being made for the nature of the disease, is also applicable to 'us', and to COVID-19 specifically.

Begin with three elementary facts about APHP.

First, it is concerned with mortality and morbidity from all sources and not merely from one source. All deaths matter, so to speak.

Second, APHP does not seek to minimise deaths, but rather to maximise population health (or to minimise ill health, as the case may be). These two ideas may diverge both because APHP takes account of morbidity as well as mortality and because different deaths are disvalued differently in a population health framework. APHP is concerned with life years (whether lived, in the case of QALYs, or not lost, in the case of DALYs ${ }^{12}$ ) rather than with lives. As such, APHP is concerned with extending lives to the greatest extent possible, and aggregating the resulting gains across people, not merely avoiding deaths. The APHP is a consequentialist framework that pays no attention to how life years are gained, or lost, but simply to how many there are.

Third, APHP is, all other things equal, in favour of saving younger persons' lives over older persons' lives, since this would add a greater number of life years lived (or subtract a smaller number of life years lost) to aggregate population health. Moreover, since APHP aggregates life years (lived, or not lost), it establishes an implicit rate of exchange between different persons' lives. In such a perspective, for instance, an intervention that accords a 10 -year-old an expected 70 additional years of healthy life is 'worth' seven times as much as an intervention that accords a 70-year-old an expected 10 additional years of healthy life. This feature has attracted a fair share of controversy. Nevertheless, it is implicit when the APHP is routinely applied in global health policy evaluation-without much comment, let alone resistance.

\section{Implications of the APHP}

What comes of applying the widely employed APHP perspective to the COVID-19 crisis? A number of inferences follow. Some may appear elementary but, as George Orwell wrote, 'restatement of the obvious is the first duty' of intelligent persons. ${ }^{13}$

First, any approach to addressing the crisis based on APHP must take note of adverse health consequences from all causes, including ones other than COVID-19, and the potential 'health-health' trade-offs involved. This principle has implications for assessing whether specific measures, in particular, drastic 'non-pharmaceutical interventions' (NPIs) such as lockdowns, were or are sensible, and to determining their optimal design. It requires recognising the variety of possible effects, direct and indirect (eg, of NPIs on health-seeking behaviour, unemployment, poverty and stress and thereby in turn on death and disease) and that these potentially operate with long and variable lags.

There is already a growing literature cataloguing and quantifying unintended consequences of NPIs implemented in response to COVID-19. One focus has been evidence that immunisation programmes and other aspects of healthcare delivery are being disrupted. ${ }^{14} 15$ It is increasingly well documented that social and health costs, including deaths, have resulted inadvertently, and likely to an extent avoidably, in certain countries. ${ }^{16}$ Such costs would have to be balanced against perceived benefits within the consequentialist framework of the APHP. An 'optimal' programme of NPIs would be arrived at by weighing the marginal health benefits and costs entailed by varying each dimension of their implementation (such as duration, stringency and other design features), taking note of both direct and indirect consequences. Although such an exercise is, at the outset of a pandemic, inherently speculative, an attempt to chart the nature and extent of possible consequences, so as to design policies on the basis of an appropriately comprehensive view, is essential. Unfortunately, there is little evidence of such an advance or early-stage planning effort having taken place in any country in relation to NPIs. We shall return to this issue later.

Second, interventions that raise the average number of life years lived in a population even by a small number on average, or avoid small losses on average, may easily save as many life years as measures that diminish the prevalence of COVID-19. One assessment (for the USA) suggests that 12.3 healthy life years may be lost on average per person who dies from COVID-19. ${ }^{17}$ To make a generous estimate of the potential losses due to COVID-19, as favourable as possible to large scale NPIs, suppose that in the absence of intervention fully $1 \%$ of the population would die of the disease in a single year, roughly doubling the number of deaths otherwise expected in the USA. This allowance is $35 \%$ higher than the most dramatic estimates of potential mortality due to the virus. ${ }^{18}$ Make a further assumption favourable to NPIs against COVID-19, contrary to the fact, that they reduced deaths from the disease to zero. Even in this scenario, any other measure that added an eighth of a healthy life year per person, on average, for the rest of the population would generate as great a population health benefit.

Putting it another way, within such a framework, avoiding life years lost from COVID-19 is justifiable at great cost-including in terms of the health of others in the population-but not at any cost. Interventions that sacrifice more than a certain quantity of healthy life years per person in the remainder of population will not be justifiable in APHP terms because they will worsen aggregate population health. Such a cost could arise, in the 
scenario considered above, if 1 in 8 persons in the society lose at least one healthy life year as a result of a 'lockdown' or other measures undertaken to prevent coronavirus deaths. It is not difficult to imagine reasons for such losses, because of the impact of the drastic steps taken on healthcare delivery, social isolation, poverty and unemployment or other factors.

Third, since COVID-19 has disproportionately higher mortality rates among the elderly, the number of life years lost from the disease will be lower than for a disease that causes the same number of deaths among younger people. If as assumed earlier 12.3 healthy life years are lost on average per person who dies from COVID-19, then a disease striking children and causing one-fifth the number of deaths, but costing 65 healthy life years for each such child, would cause a greater impact on aggregate population health. If an action to avoid COVID-19 deaths results inadvertently in additional deaths among the young, the larger number of life years lost due to each such death must be taken into account when determining the net impact on population health. It appears unlikely that interventions against COVID-19 would be judged to have an adverse impact for this reason alone-at least in the short run-since to do so they would have to result in a large increase in deaths of the young. The greater impact of inadvertent increases in mortality or morbidity among the young is, however, a factor that should be taken into account when assessing the effect of NPIs on aggregate population health, and when designing them so as to avoid costly 'collateral damage' to aggregate population health.

\section{PROPORTIONALITY}

The APHP demands that efforts to address different threats to population health be suitably balanced. If our efforts are disproportional to their impact, then shifting them can enhance aggregate population health. Proportionality must be applied in three different kinds of comparisons (in each of which the implications of the APHP must be considered). These are proportionality at a moment in time, proportionality over time and proportionality over space.

Proportionality at a moment in time requires that distinct simultaneously present threats to aggregate population health are given appropriate attention. Proportionality over time requires that threats to aggregate population health which are present at different moments are given suitable attention (in particular, by not advancing population health at one moment at its expense at other moments). Proportionality over space requires that threats to aggregate population health arising in different places within the scope of concern all gain adequate attention.

Balancing efforts of different kinds would not be needed if improved outcomes in one area could always be attained without any loss in another area. It is precisely because this is not always possible that a question of trade-offs arises, at least in the short run. For instance, medical personnel, hospital beds or production capacity for medical supplies may be restricted, there may be a limited government budget to be spent, or the measures taken to reduce deaths from one source (eg, a lockdown) may give rise to increased deaths from another source (eg, because a lockdown impedes health services or causes poverty). Whether a sensible balance has been struck is a question of both the evaluative framework and the empirical facts concerning trade-offs.

Can the efforts taken during COVID-19 crisis be considered to be proportionate in these three respects?

\section{Proportionality at a moment}

Policies for advancing aggregate population health maximally must focus on distinct health objectives at any one moment, distributing the efforts made so that they are proportionate to their incremental impact. One means of assessing this is to examine the implicit or explicit expenditure of societal resources in relation to distinct threats to health. A balanced approach to promoting aggregate population health should distribute societal efforts (eg, financial or administrative resources expended) across interventions so that the additional units of aggregate population health that they generate, or protect, per unit of effort (eg, financial sacrifice or administrative attention), taking into account all of their direct and indirect consequences, is equalised. Otherwise, a change in approach would enhance aggregate population health. The aim of a balanced approach is to implement the appropriate trade-off between different efforts to protect or to improve aggregate population health.

Various proposals have been made for the reference cost or threshold per QALY that might be used to determine whether the application of curative health interventions is 'cost effective'. The appropriate trade-off between health and non-health considerations in society is sometimes a focus of such proposals. Interventions that are more expensive than this threshold are required, in some health systems, to face a demand for additional justification, whereas interventions that are less expensive are presumed worthwhile. ${ }^{19}$ It appears that in some countries some curative interventions that do not pass this hurdle are not being offered or undertaken.

There is, however, an entirely different point of view from which such a threshold may be of interest. It may also be interpreted as a norm or a 'shadow price', reflecting the number of QALYs per dollar which ought to be generated (equally) by the available interventions when balanced health policies that maximise aggregate population health at a societally desired level are in place. This norm can be used to assess whether the available health resources are being presently distributed in such a manner as to achieve the presumed societal goal.

According to such a test, there is evidence that the pattern of health expenditures of societies is far from maximising aggregate population health. If commonly used reference standards for the permissible cost of 
achieving a QALY are employed, then preventative health expenditures appear to be below this threshold. ${ }^{20-22} \mathrm{~A}$ very modest allowable threshold would be US $\$ 10000$ per QALY. (Thresholds used in high-income countries vary from around US $\$ 40000$ in European countries to US $\$ 125000$ and higher in the USA). If it is assumed that there exist preventative interventions, such as efforts to change unhealthy behaviours, which can feasibly add one QALY to each person's life, this would suggest that it would be worth expending US\$10000 per person on preventative health expenditures to achieve this goal. But such an additional expenditure on preventative healthcare would near or exceed existing total health expenditure in every country. In Canada, for example, total health expenditure was estimated at US $\$ 193$ billion or just over US $\$ 5000$ per person in $2019 .{ }^{23}$ The USA has the highest per capita health expenditure in the world, just above US $\$ 10000 .^{24}$ The actual expenditure patterns of countries suggest that they are not spending as much on improving aggregate population health as the valuations that they claim to assign to additional QALYs would suggest that they should.

This reluctance to devote economic resources to prevention of mortality and morbidity appears to have been overcome in relation to COVID-19. Most countries have already experienced sizeable economic costs as a result of the response to COVID-19. Whether these costs exceed the level that according to conventional APHP criteria is considered appropriate for an intervention to reduce disease risks will have to be studied.

Begin with an example of a single country, the USA, again making assumptions that are as favourable as possible to the massive societal efforts that have been witnessed against COVID-19. Assume that 2 million lives will have been saved in the USA alone during the first year of the pandemic by the implementation of NPIs. This number is based on the influential early estimate of the number of deaths resulting from an 'unmitigated' scenario-in which no government mandated NPIs were undertaken ${ }^{18}$ - combined with the premise that this will have been reduced to 200000 deaths in the USA during this year as a result of NPIs (if the mortality ends up being different, that will change the specific numbers that result but not the point). It would follow that NPIs had led to 24.6 million QALYs having been saved (on the earlier assumption of 12.3 life years saved per life saved). If a threshold of US\$125000 per QALY (on the lower end of the range of values employed in the USA, ${ }^{172425}$ but high in comparison with those used in other highincome countries, which can be less than one-third of this) is applied, the total cost that is 'warranted' to save these QALYs is just less than US\$3.1 trillion. If twice the cost per QALY is allowed, then the permitted societal cost is little less than US\$6.2 trillion.

Even a conservative estimate of the economic costs of the policy response to COVID-19-without taking into account their distributional and social consequences-already exceeds the lower threshold and may well approach or exceed the upper one. The direct expenditure of the US federal government on an economic stimulus and compensation package to respond to the crisis is all by itself at least US $\$ 2.3$ trillion and may be closer to US $\$ 3$ trillion. ${ }^{2627}$ This expenditure is widely viewed as inadequate to make up for the societal economic losses experienced. Adding the losses of income due to aggregate economic contraction will lead to a much higher estimate of economic costs. The International Monetary Fund predicts a reduction in US GDP this year of almost $8 \%$, or more than US $\$ 1.64$ trillion. ${ }^{28}$ Adding this loss of income to the direct expenditures of the federal government leads to a cost to US society of at least US\$3.84 trillion.

If the cost is taken instead to be given by the shortfall from the output that would have been expected in the absence of a crisis, then the amount is even larger. The US Congressional Budget Office has estimated a gap with potential Gross Domestic Product of 7.4\% in 2020 and $6.2 \%$ in 2021 , for a total of $13.6 \%$ over 2 years, or around US $\$ 2.75$ trillion. ${ }^{29}$ Adding this loss of income to the direct expenditures of the federal government leads to a cost to US society of at least US $\$ 5.75$ trillion. In either case, these estimates ignore direct expenditures undertaken by other levels of government, businesses and individuals. Nevertheless, these estimates both exceed the previously mentioned US\$3.1 trillion expenditure, the maximum warranted if the permitted cost per QALY (applied to other health interventions) is US $\$ 125000$. Moreover, the latter estimate approaches the maximum expenditure warranted even if an amount per QALY that is double the value is employed.

Similar calculations could be undertaken for other countries. The International Monetary Fund (IMF) predicts a $4.9 \%$ reduction in world GDP this year as a direct result of lockdowns, or more than US\$ $\$$ trillion at market exchange rates. ${ }^{28}$ The gap with potential output that has arisen as a result of the policy response would be greater. If a world growth rate of $2 \%$ is assumed as the counterfactual for 2020 (the world growth rate was 3.1\% in 2018), then the cost of NPIs would exceed US $\$ 5$ trillion, more than the total worldwide public expenditure on health prior to the crisis of US $\$ 4.7$ trillion. ${ }^{30}$ The total costs of NPIs introduced in response to COVID-19 globally are likely, according to this measure, likely to be greater than the scale of total public efforts on all other health issues.

A more precise estimate of the economic costs should take note that they would have been experienced to an extent even under an 'unmitigated' strategy-for instance because individuals would have chosen of their own accord to lessen their social interactions and economic activities-but by the same token the benefits of NPIs would also be reduced against such a baseline. The net impact of these two effects is therefore not straightforward to judge. This proviso underlines that any estimate unavoidably involves counterfactual judgements, and contestable models. Estimates of the kind we have presented are merely starting points. 
If higher valuations per QALY are used, higher allowances for costs warranted to save QALYs will be generated. The merit of saving life years or lives is not contested here. Still less do we advocate for or against a specific societal valuation of life. Instead, we ask: if the public health is conceived in terms of aggregate population health, are efforts taken against COVID-19 suitably proportional to those taken to preserve and extend it through other means, as demanded by the APHP approach? We refer to dollars expended per QALY gained by different interventions only to provide a test of whether this is the case.

As noted earlier, NPIs are likely to have led to noncoronavirus-related health costs in addition to direct dollar expenditures. These may arise from diverse sources, many of which may have medium-term and long-term consequences that are not yet visible, through preventative and curative services addressing other health conditions, the impact of unemployment and poverty on physical and mental health, the impact of lockdowns on domestic abuse, use of addictive substances, physical activity and social isolation, the effect of interruptions to schooling, and many other factors. The relevant media reports, action research and emerging academic research are already difficult to summarise. It is noteworthy that even some who had focused earlier on COVID-19 impact alone have belatedly begun to address the impact of the response on other aspects of health. ${ }^{31}$ There is reason to believe that these non-coronavirusrelated health consequences, some potentially very sizeable, were largely if not wholly overlooked in the early stages of the response to the pandemic, and that they are still receiving inadequate attention. Since the presence of adverse non-coronavirus-related health consequences of NPIs increases the 'hurdle' for their justification, the optimal implementation of NPIs must reflect the balance of all of their costs and benefits.

If the possibility of adverse health and non-health consequences of broad-based NPIs had been more adequately recognised at the outset, their effects might have been mitigated through suitable policy design and complementary measures. 'Smart policies' can help to reconcile various goals, limiting damage to population health from COVID-19 while addressing other health concerns, including those directly or indirectly dependent on economic and social activity. To take one example, a 'protective belt' can be created around nursing homes, in which there has been disproportionate mortality in many countries, through frequent testing and support of personnel so that they can minimise commuting and broader social contacts. ${ }^{32}$ There is little evidence that such possibilities for more focused protective approaches were seriously considered in most countries, despite the knowledge having been present very early on that the elderly were particularly vulnerable table 1). ${ }^{18}$ Many of the measures implemented worldwide appear to have been sweeping in nature. ${ }^{33}$

This may have been in part due to the paucity of options presented to policymakers by experts: NPIs such as wholesale closures of schools and workplaces, which neglected other options such as widespread testing or mask wearing, which had already been adopted in some countries, as well as the more targeted possibilities just discussed table $2 .{ }^{18}$ The epidemiological studies that were used most prominently to guide policy appear to have taken no account whatever of the potential impact of the NPIs proposed on non-coronavirus-related health consequences. ${ }^{18}$

The importance given to addressing a specific threat to health and the appropriate trade-offs to be made between such threats depend within the APHP not only on values but also on empirical facts, for example concerning the social and demographic profile of a society. For instance, the APHP recommends that lesser weight be given to diseases that affect the elderly disproportionately in regions with a lower share of elderly in the population. The proportion of the population over 65 is $20 \%$ in Europe, it is $16 \%$ in North America and it is $11 \%$ in East Asia. In contrast, the proportion of the population over 65 is around 3\% in sub-Saharan Africa, $6 \%$ in South Asia and 5\% in the Middle East and North Africa. $^{34}$

The APHP necessarily must derive from these sizeable differences conclusions that vary according to world region as to the effort to be expended on averting different threats to health. The WHO, despite its own embrace of the APHP in recent years, does not appear, to the best of our knowledge, to have given any attention to this point in its recommendations for the response to COVID-19 globally.

The possible adverse distributional consequences of 'lockdowns' and other broad and untargeted policies, in terms of their effects on the already poor, the already unhealthy or both, raise additional concerns not taken into account of by the APHP in its standard version (which merely adds life years across persons, indifferent to who those persons are). The cost being borne, whether in terms of direct and uncompensated economic losses, or in terms of ultimate health consequences, is not merely an abstract cost for 'society' but involves specific, perhaps great or greater, sacrifices for particular persons.

If an evaluation of policies is to reflect health equity concerns, it must take directly into account who is affected and how, both by COVID-19 and by the measures taken against it. This would require directly valuing equity among persons by taking note of how many QALYs and DALYs are experienced by different people and not only of how many in total there are. The APHP in its customary form views people as interchangeable sites for the production of interchangeable units (such as QALYs or DALYs) consonant with its utilitarian antecedents. ${ }^{35}$ A properly equity-sensitive approach would in contrast require departing from these accustomed 'sum-ranking' versions of the APHP. Taking equity considerations into account explicitly will influence how burdens and benefits are conceived when identifying and aggregating them. 


\section{Proportionality across time}

Are the efforts being undertaken to address a given risk to health today (in this case COVID-19) proportionate to other efforts that have been undertaken in the past and those planned for the future? The goal of improving aggregate population health must necessarily be pursued over time. Health is experienced throughout time and it depends causally on both present and past actions. The application of efforts over time, valuing all lives and life years, whenever they may be experienced, is necessary both for equity (across generations) and, in the APHP, for efficiency (to achieve the greatest quantity of aggregate population health, conceived comprehensively, as possible).

Consider, for example, efforts made to promote the health of children, which contribute to their health throughout their lives. An intertemporally efficient dynamic programme to maximise aggregate population health over time should note that such interventions contribute to aggregate population health right away and also in the future. The APHP requires that investment in health be distributed over time, both because life years matter whenever they are lived and because of causal interdependence between health investments made at different times.

If there are special opportunities to promote or protect health which arise at a specific moment, these may be taken account of by the APHP. For example, a newly arising disease such as COVID-19 creates a new source of potential losses to aggregate population health, and may therefore generate possibilities to save life years that would otherwise be lost. Life years may be saved in this way, up to a point, more easily than saving life years in other ways. (Consider, for example, how providing basic information to the public about the methods of transmission of the disease, all by itself, could save quite a number of lives). But if efforts to protect population health today come at the cost of future efforts then they must be proportionate.

A consistent 'maximising' plan over time of societal efforts to improve population health must be such that if great effort is undertaken to avoid life years lost due to COVID-19, corresponding effort should have been applied to addressing other causes of death before this crisis-if interventions were available to do so at similar or lower costs-and corresponding effort should also be applied to addressing other causes of death after this crisis-if interventions are available to do so at similar or lower costs. Otherwise, the redirection of some of these efforts to other points in time would have enhanced, or will enhance, aggregate population health.

Whether or not efforts made yesterday, today and planned for tomorrow stand in the suitable proportion must be assessed in light of the objective of population health, the opportunities to protect or to enhance health that are available at each moment, the valuation of life years lived at different times and the possibility for 'transferring' societal resources are not used at one moment to other points in time. For instance, if there are steps that can reduce deaths and thereby improve population health during a pandemic, with little cost to future population health, this is an opportunity that must be grasped. On the other hand, if such steps would be costly to future population health, then this must be considered. The cost per QALY gained at each moment through each means must be registered in a comprehensive evaluation of aggregate population health over time.

The policy response to COVID-19 has led to economic contraction, decreases in government revenue and increases in fiscal expenditures in a wide range of countries. This has resulted both from the economic effects of their own NPIs and the effect of those applied elsewhere, due to interlinkages between economies. One consequence has been a decrease in the sustainability of debts in a number of developing countries (as a result of which temporary debt relief measures have been adopted for eligible countries). ${ }^{36} \mathrm{~A}$ shrinking 'envelope' for future fiscal expenditures implies that public efforts to protect aggregate population health tomorrow may be more difficult to implement as a direct result of efforts to protect it from COVID-19 today. Even in high income countries, where health expenditures are customarily greatest, ${ }^{37}$ efforts to address the risk presented by COVID-19 may come at the cost of future health priorities. Determining the proportionality of present and anticipated future efforts to address aggregate population health is an unavoidable demand of a comprehensive assessment of the effectiveness of policies to promote aggregate population health in the presence of constraints, even ones that are to a degree revisable.

A comparison of historical and contemporary mortality rates is informative. Even the most pessimistic early estimates of the excess mortality likely to result from COVID19 , in the absence of any interventions to diminish its spread (the 'no mitigation' scenario), anticipated an increase in global mortality of about $70 \%$, or around 40 million persons. ${ }^{38}$ If such a scenario were to come true, the crude mortality rate would rise to what it had been in 1980. Even in 2000, world crude death rates were $15 \%$ higher $(8.647$ per 1000$)$ than at present $(7.546$ per 1000). ${ }^{39}$

Were these mortality rates treated as a crisis then, occasioning massive societal expenditures to reduce them? Current health expenditures as a percentage of world income have increased marginally in the intervening period (from $8.6 \%$ to $9.9 \%$ ). ${ }^{34}$ Aid has stagnated over the same period, falling from $0.35 \%$ of Organisation for Economic Cooperation and Development countries' GDP in 1980 to $0.22 \%$ in 2000 before partially recovering to $0.31 \%$ in 2017 (although this may be a generous estimate, as a change of definition has allowed more expenditures to be classified as Official Development Assistance) ${ }^{40}$ In contrast, governments' direct expenditures in response to the pandemic could quite easily surpass trillions of dollars, or many percentage points of 
the global GDP of more than US $\$ 80$ trillion (at market exchange rates). ${ }^{41}$

It is far from obvious that yesterday's mortality rates were treated as an emergency to the same extent as COVID-19 has been, even if they ought to have been. The limited expenditure on reducing mortality previously seems difficult to square with the enormous effort to avoid mortality today, even allowing for unusual opportunities to avoid mortality by checking a pandemic not present in 'normal' times. It might be suggested that COVID-19 has somehow awakened a higher societal valuation of QALYs than previously. Although this offers a roundabout way to rationalise the observed behavioural pattern, if there were a 'representative agent' accounting for it, the resulting tale seems less than plausible as a way to claim an intertemporally consistent aggregate health maximising programme of actions. It would moreover demand immediate and hereafter increased societal expenditure on achieving aggregate population health .

A further issue concerns the fact that coronavirus deaths seem to be heavily concentrated, leading to enormously elevated mortality figures over brief periods ${ }^{42}$ which may not be sustained. Such bunching may result in disturbing consequences, such as hospitals and morgues at capacity, leading to excess mortality for a time, and creating an atmosphere of emergency. (Some of these may be deaths 'borrowed from the future', as some of those who have died may well have died of other causes in the near term if they had not died of, or with, COVID-19, but how much is difficult to know.) From the perspective of the APHP there is no reason to take action to prevent deaths that are concentrated in time any more than to prevent deaths that are distributed over time.

The APHP may not provide a framework that can make sense of observed societal efforts to protect aggregate population health at some times more than at others, but if it cannot then we can only conclude that either our actions or the APHP itself require rethinking.

\section{Proportionality across space}

Efforts to address COVID-19 also raise the question of whether they are proportionate in the sense that they are applied with adequate evenness across space, to protect and promote the health of subpopulations living in different places, so as not to sacrifice overall aggregate population health. Equity concerns related to who experiences life years and not just to what their sum total is may enhance the case for such evenness. Of course, much hangs on what is the definition of the relevant 'population'. For those who espouse ethical universalism in some degree, it is that of the whole world. For example, even those who believe that priority should be attached to one's fellow citizens may agree that some importance should be given to others (a 'concentric circles' view expressing different degrees of moral concern for those at different distances) ${ }^{43}$ It is important to note, however, that the APHP does not generally admit of such distinctions, taking instead the view that a life year is a life year is a life year, whoever experiences it. This perspective should, if taken on its face, presumably be applied to life years experienced anywhere in the world.

The cost of saving lives (or generating QALYs) in lowincome and middle-income countries is likely to be rather lower than in an advanced country, because of the lower cost of medical and social services and because of the often more easily prevented or cured nature of the diseases suffered. ${ }^{44}$ Valuing lives equally everywhere in the world and seeking to mazimize world population health would mean directing all incremental health resources toward enhancing population health in such countries. If it is not the case that we spend the amounts everywhere that we should to treat 'a life year as a life year as a life year, ${ }^{45}$ is it because we in fact value lives 'there' less, whatever rhetoric we may habitually employ (in which case a different account is needed of what 'our' values in fact are)? Alternatively, is there a slip between cup and lip, so that actions do not conform to values? Or do we have health goals other than to maximize world population health?

What are the implications for evaluating the response to COVID-19? Taking account of the effects of policies on 'distant others' would require considering the aggregate population health of the world as a whole as an 'as if' objective, and as a result to consider both the trade-offs and the complementarities between efforts to improve health (whether by attacking COVID-19 or by addressing other risks to health) in one place and another. A dollar spent in the form of expenditures on attacking the pandemic in one country might be considered to be a substitute (as it could have been spent in another country) or a complement (as it could result in positive spillovers, for example by reducing the risk of future cross-border transmission). Or consider that a dollar lost due to economic contraction in one country may have knock-on implications, due to reduced remittances or imports in another country, leading in turn to health consequences.

The promotion of the aggregate population health of the whole world requires keeping in mind all of the distinct 'marginal conditions' for optimisation, which depend both on the various causal relationships that are present and on the manner in which the aggregate population health of each country figures normatively in the overall objective of global population health. We know that, empirically, no government in the world appears to hold global public health as its objective in this way, and still less do they all coordinate to promote that goal. Nevertheless, comparing the world we live in with this unrealised image underlines the gulf between our fragmented 'nationalist' pursuit of the public health and what a 'universalist' interpretation of aggregate population health would demand.

\section{WHAT DO OTHER PERSPECTIVES OFFER?}

If the current efforts to arrest COVID-19 are not wholly straightforward to justify in terms of the APHP, are there other frameworks which can be drawn on in this task? 
Consider, for instance, the distinction between killing and letting die, with the former often thought, absent particular reasons, to be morally especially important to avoid ('First, do no harm'). Might it be that some deaths, in the context of global health, are of the first kind and others are of the second kind, in which case disproportion in efforts may be justified? It is far from obvious that this offers a way out. Actions to avoid deaths both from COVID-19 and other illnesses may plausibly fall under either heading. For instance, it has been widely argued that preventing deaths from COVID-19 requires that hospital capacities be enhanced (so that persons are not allowed to die) and that social interactions be avoided (so that persons are not killed by being infected).

Deaths from other causes similarly seem to arise as a result of both culpable action and inaction, for instance due to our individual and collective responsibility for causing environmental damage, contributing to political or economic processes ${ }^{46}$ that produce poverty and inequality (or at least do nothing to correct it) and so forth. Almost every cause of death and ill health, including but not limited to infectious diseases such as COVID-19, is also influenced by social and environmental factors. In many cases the chains of causation involved are complex and therefore obscure, but nonetheless surely present. ${ }^{47}$ These causal links can extend across the entire globe and influence present as well as future generations, perhaps through long and variable lags.

It is challenging to describe fully both the ways in which we contribute to particular outcomes and whether it is our action or our inaction which is of greater causal and evaluative significance. In practice, therefore, such a distinction may be of limited use to determine what public health actions to prioritise. Regardless of our moral concerns, we will have to pursue broad-based and balanced efforts to improve the health of people, paying due attention to the different threats they face, whoever they are and wherever they live.

Other frameworks for evaluation are also likely to direct us to give balanced attention to diverse health priorities, although the specifics of what is demanded will vary. For instance, a 'fair innings' approach, focusing on offering all the chance to live what it deems a reasonable length of healthy life, is likely to give greater importance to avoiding threats to health which cause death at younger ages, even if it gives some attention to threats to health from all sources, and for all people, just as the APHP does. ${ }^{48}$

One need not endorse any one such specific alternative to see that putting aside the APHP-for which there may be good reasons-does not offer a ready resolution to the question of whether there is a basis to justify the more sweeping measures taken to address COVID-19. The call for proportionality arises, if for different reasons, when applying other frameworks for evaluation too. ${ }^{49}$

So far, we have taken no special account of the great uncertainty that was present at the onset of the global pandemic. ${ }^{50}$ This uncertainty remains, although it is diminishing slowly as knowledge is gained about how the disease is transmitted, the risks that are attached to having it, and so on. Uncertainty may warrant taking steps that are prudential in nature, to avoid permitting disasters to arise which are foreseeable to a degree, although their likelihoods may be unknown. We may be morally responsible to take such protective measures. ${ }^{51}$ But uncertainty also provides reasons for adopting flexible approaches that can be adjusted as relevant information is gained and, crucially, for making adequate provision to collect such information, so as to avoid entrenching errors. It is not obvious how much attention has been given to this in the policy response to COVID-19. ${ }^{52}$

It is noteworthy that other established threats to the public health which are similarly subject to great, even arguably lesser, uncertainties-notably climate change ${ }^{53-55}$-have not elicited a sweeping prudential response in the name of the public health. Economic costs and remaining uncertainties have sometimes been pointed to as arguments against such a response, but do not seem compelling from the health perspective. There is a strong case that climate change will most harm the poorest and otherwise vulnerable in the world. This does not seem to be the case for COVID-19, if only for the reason that poorer regions have a smaller share of elderly persons. It is hard to make sense of the asymmetry between the responses in the two cases, even after having taken into account the different timescales on which their effects may be felt. The existence of uncertainty, and in particular the difficulty of ruling out disastrous 'downside' possibilities cannot justify a prudential response to COVID-19 without seeming to demand a similar response in relation to other threats to global public health, notably climate change. This is an argument for proportionate action against both threats, and not for inaction against either.

\section{CONCLUSION}

Recent policies to address COVID-19 are difficult to reconcile wholly with the aggregate population health frameworks that are widely used in global health analysis and policy. It is not obvious that alternative ethical frameworks can readily justify the policy choices that have been made. This raises questions about how the response to the current pandemic should be adjusted and how future pandemics should be approached.

Applying the APHP to assess the sweeping measures taken against COVID-19 raises serious questions. Those who promote the APHP may find it necessary either to assess such policies more critically or to revise their stated goals, or both. This in no way requires the abandonment of an active, determined response to COVID-19, or indeed any future pandemic. Rather, both scholars and decisionmakers must take a balanced and holistic approach to the public health, beginning with attempting early in any intervention to anticipate the range of effects, both direct and indirect, of policies. Such scenario building, as well as 
subsequent monitoring and ongoing adjustment of policies, and the development of complementary measures to minimise health costs and maximise health benefits, requires collaboration across disciplines to achieve an integrated view of the causal pathways at work, and their likely effects. It does not appear that efforts at comprehensive assessment were at all involved in designing the early policy response to COVID-19. Efforts to monitor and to adjust these policies are still needed. A proportionate approach to the aspects of the public health must guide our response, in this crisis and ones to come.

Twitter Sanjay G Reddy @sanjaygreddy

Contributors I am the sole author of this work.

Funding The authors have not declared a specific grant for this research from any funding agency in the public, commercial or not-for-profit sectors.

Competing interests None declared.

Patient consent for publication Not required.

Provenance and peer review Commissioned; internally peer reviewed.

Data availability statement All data relevant to the study are included in the article.

Open access This is an open access article distributed in accordance with the Creative Commons Attribution Non Commercial (CC BY-NC 4.0) license, which permits others to distribute, remix, adapt, build upon this work non-commercially, and license their derivative works on different terms, provided the original work is properly cited, appropriate credit is given, any changes made indicated, and the use is non-commercial. See: http://creativecommons.org/licenses/by-nc/4.0/.

ORCID iD

Sanjay G Reddy http://orcid.org/0000-0002-3270-143X

\section{REFERENCES}

1 Murray CJ. Quantifying the burden of disease: the technical basis for disability-adjusted life years. Bull World Health Organ 1994;72:429-45.

2 Murray CJL, Lopez AD. The Global burden of disease : a comprehensive assessment of mortality and disability from diseases, injuries, and risk factors in 1990 and projected to 2020. World Health Organization, World Bank \& Harvard School of Public Health, 1996.

3 Murray CJL, Salomon JA, Mathers CD, et al. Summary measures of population health concepts, ethics, measurement and applications. World Health Organization, 2002. https://apps.who.int/iris/handle/ $10665 / 42439$

4 Lopez AD, Mathers CD, Ezzati M. Global burden of disease and risk factors. The World Bank and Oxford University Press, 2006. https:// www.ncbi.nlm.nih.gov/books/NBK11812/

5 Zeckhauser R, Shepard D. Where now for saving lives? Law Contemp Probl 1976;40:5-45.

6 Anand S, Hanson K. Disability-adjusted life years: a critical review. J Health Econ 1997;16:685-702.

7 Parks R. The rise, critique and persistence of the DALY in global health. J Glob Health 2014.

8 WHO (2018). "WHO and IHME collaborate to improve health data globally". Available: http://www.healthdata.org/news-release/whoand-ihme-collaborate-improve-health-data-globally

9 Tan-Torres Edejer T, Baltussen R, Adam T. Making choices in health: WHO guide to cost-effectiveness analysis. World Health Organization, 2003. https://www.who.int/choice/publications/p_ 2003 generalised cea.pdf

10 Wenar L. What we owe to distant others. Politics Philos Econ 2003;2:283-304.

11 Gates Foundation. Global health strategy overview, 2010. Available: https://docs.gatesfoundation.org/Documents/global-health-strategyoverview.pdf

12 Anand S, Reddy SG. The construction of the DALY: implications and anomalies. Working paper, International inequalities Institute, London school of economics, 2019. Available: http://eprints.Ise.ac. uk/101878/
13 Orwell G. Review of Power: a new social analysis by Bertrand Russell. Adelphi University, 1939.

14 Hoffman J, MacLean R. Slowing the coronavirus is speeding the spread of other diseases. The New York Times, 2020.

15 WHO. "At least 80 million children under one at risk of diseases such as diphtheria, measles and polio as COVID-19 disrupts routine vaccination efforts, warn Gavi, WHO and UNICEF", 2020. Available: https://www.who.int/news-room/detail/22-05-2020-at-least-80million-children-under-one-at-risk-of-diseases-such-as-diphtheriameasles-and-polio-as-covid-19-disrupts-routine-vaccination-effortswarn-gavi-who-and-unicef

16 Ray D, Subramanian S. India's lockdown: an interim report, 2020. Available: https://debrajray.com/wp-content/uploads/2020/05/ RaySubramanian.pdf [Accessed 15 Jun 2020].

17 Goldstein J, Lee R. Under review at proceedings of the National Academy of sciences, 2020. Available: https://www.nber.org/papers/ w27043

18 Ferguson N. Report 9 - impact of non-pharmaceutical interventions (NPIs) to reduce COVID-19 mortality and healthcare demand. working paper, imperial college MRC centre for global infectious disease analysis, 2020. Available: https://www.imperial.ac.uk/mrcglobal-infectious-disease-analysis/covid-19/report-9-impact-ofnpis-on-covid-19/

19 Ogden J. QALYs and their role in the NICE decision-making process. Prescriber 2017;28:41-3.

20 Owen L, Morgan A, Fischer A, et al. The cost-effectiveness of public health interventions. J Public Health 2012;34:37-45.

21 Owen L, Fischer A. The cost-effectiveness of public health interventions examined by the National Institute for health and care excellence from 2005 to 2018. Public Health 2019;169:151-62.

22 MacMonegle AJ, Nonnemaker J, Duke JC, et al. Cost-effectiveness analysis of the real cost campaign's effect on smoking prevention. Am J Prev Med 2018:55:319-25.

23 Canadian Institute of Health Information. Health spending, 2019. Available: https://www.cihi.ca/en/health-spending\#: :text= In\%202019\%2C\%20total\%20health\%20expenditure,report\% 20National\%20Health\%20Expenditure\%20Trends

24 Institute for Clinical and Economic Review. 2020-2023 value assessment framework, 2020. Available: https://icer-review.org/ wp-content/uploads/2019/05/ICER_2020_2023_VAF_013120-4. pdf

25 Viscusi WK. Pricing lives: guideposts for a safer society. Princeton University Press, 2018.

26 New York Times. A \$2 trillion lifeline will help, but more may be needed. by Jim Tankersley, 2020. Available: https://www.nytimes. com/2020/03/25/business/2-trillion-stimulus-coronavirus-bill.html

27 Financial Times. US treasury plumps for longer-term debt to fund \$3tn stimulus, 2020. Available: https://www.ft.com/content/ f0b902de-98fc-48fc-a70c-705d88027d48

28 International Monetary Fund. World economic outlook, April 2020: the great lockdown, 2020. Available: https://www.imf.org/en/ Publications/WEO/Issues/2020/04/14/weo-april-2020

29 Huang C. Putting the size of the needed COVID-19 fiscal response in perspective. Center on budget and policy priorities, 2020. Available: https://www.cbpp.org/research/federal-budget/putting-the-size-ofthe-needed-covid-19-fiscal-response-in-perspective

30 World Health Organization. Global spending on health: a world in transition, 2019. Available: https://www.who.int/health_financing/ documents/health-expenditure-report-2019.pdf?ua=1\#: :text=It\% 20was\%20US\%24\%207.8\%20trillion,US\%24\%207.6\%20trillion\% 20 in $\% 202016$.\&text=The\%20health\%20sector\%20continues \%20to, economy\%20grew\%203.0\%25\%20a\%20year

31 Hogan A. Report 19: the potential impact of the COVID-19 epidemic on HIV, TB and malaria in low- and middle-income countries. working paper, imperial college MRC centre for global infectious disease analysis, 2020. Available: https://www.imperial.ac.uk/media/ imperial-college/medicine/mrc-gida/2020-05-01-COVID19-Report19.pdf

32 Reddy SG. Lockdowns are costing us. it is time to be smart, 2020. Available: https://www.barrons.com/articles/lockdowns-are-costingus-its-time-to-be-smart-51590193324

33 Our World in Data. Policy responses to the coronavirus pandemic, 2020. Available: https://ourworldindata.org/policy-responses-covid

34 Bank W. Population ages 65 and above (\% of total population), 2020. Available: https://data.worldbank.org/indicator/SP.POP.65UP. TO.ZS

35 Sen A. Equality of What. In: Tanner lecture on human values. Stanford University, 1979.

36 Munevar D. G20 debt service suspension: a response not fit for purpose (I) and (II), 2020. Available: https://eurodad.org/g20_debt1 and https://eurodad.org/g20_debt2 
37 World Bank. "Current health expenditure per capita (current US\$).", 2020. Available: https://data.worldbank.org/indicator/SH.XPD.CHEX. PC.CD

38 Walker P. Report 12: the global impact of COVID-19 and strategies for mitigation and suppression. Working paper, Imperial College MRC centre for global infectious disease analysis, 2020. Available: https://www.imperial.ac.uk/media/imperial-college/medicine/mrcgida/2020-03-26-COVID19-Report-12.pdf

39 UN Department of Economic and Social Affairs. World population prospects, 2020. Available: https://population.un.org/wpp/ DataQuery/

40 OECD. Development aid drops in 2018 , especially to neediest countries, 2019. Available: https://www.oecd.org/newsroom/ development-aid-drops-in-2018-especially-to-neediest-countries. htm

41 International Monetary Fund. Policy responses to Covid-19: policy tracker, 2020. Available: https://www.imf.org/en/Topics/imf-andcovid19/Policy-Responses-to-COVID-19

42 McCann A, Wu J, Katz J. "How the coronavirus compares with 100 years of deadly events", 2020.

43 Bok S. Common values. University of Missouri Press, 2002.

44 Dreze J, Sen A. Hunger and public action. Oxford: Clarendon Press, 1989.

45 Cohen J. "A QALY is a QALY is a QALY, or is it?". Available: https:// www.forbes.com/sites/joshuacohen/2019/01/14/a-qaly-is-a-qaly-isa-qaly-or-is-it/\#61563909496a

46 Pogge T. World poverty and human rights. 2 edn. Cambridge: Polity Press, 2008.
47 Scheffler S. Boundaries and allegiances. Oxford: Oxford University Press, 2003.

48 Williams A. Intergenerational equity: an exploration of the 'fair innings' argument. Health Econ 1997;6:117-32.

49 Anand S, Peter F, Sen A. Public health, ethics and equity. Oxford: Oxford University Press, 2004.

50 Reddy SG. Coronavirus and the limits of economics, 2020. Available: https://foreignpolicy.com/2020/03/31/coronavirus-pandemicrethinking-economics/

51 Barry C, Lazar S. Justifying Lockdowns. In: Ethics and international affairs, 2020

52 Collier P. The problem of modelling: public policy and the coronavirus. Times Literary Supplement, 2020.

53 pp. Smith KRet al. Human health: impacts, adaptation, and co-benefits. in: climate change 2014: impacts, adaptation, and vulnerability. Part A: global and sectoral aspects. contribution of working group II to the fifth assessment report of the Intergovernmental panel on climate change. Cambridge, UK: Cambridge University Press, 2014: 709-54.

54 Watts N, Amann M, Arnell N, et al. The 2019 report of the Lancet countdown on health and climate change: ensuring that the health of a child born today is not defined by a changing climate. Lancet 2019;394:1836-78

55 Melillo JM, Richmond T, Yohe GW. Climate change impacts in the United States: the third national climate assessment. U.S. Global Change Research Program, 2014 